\title{
Total Knee Arthroplasty Infected by Brucella melitensis: Septic Loosening and Long-Term Results of Two-Stage Revision Knee Arthroplasty
}

Fatih Karaaslan $^{1^{*}}$, Musa Uğur Mermerkaya ${ }^{1}$, Sinan Karaoğlu ${ }^{2}$ and Mehmet Ayvaz ${ }^{3}$

${ }^{1}$ Bozok University Faculty of Medicine, Department of Orthopaedics and Traumatology, TR-66200, Yozgat, Turkey

${ }^{2}$ Memorial Kayseri Hospital, Department of Orthopaedics and Traumatology TR-38010, Kayseri, Turkey

${ }^{3}$ Hacettepe University Faculty of Medicine, Department of Orthopaedics and Traumatology, TR-06100, Ankara, Turkey

\begin{abstract}
Brucella infection associated with arthroplasty is a rare event. An unspecific clinical symptomatology is associated with unclear radiographic signs of periprosthetic bone halisteresis. Only a positive anamnesis combined with an antibiogram of the joint liquid and a high serum antibody titer can lead to a definitive diagnosis. We herein report a case of Brucella melitensis infection in a patient who underwent total knee arthroplasty 2 years earlier. Plain radiography and bone scintigraphy confirmed septic loosening. The patient was successfully treated with two-stage revision arthroplasty.
\end{abstract}

Keywords: Brucella; Arthroplasty; Infection; Two-stage revision; Antibiotic therapy

\section{Introduction}

Infection following total knee arthroplasty (TKA) is one of the most common and important complications in orthopedic surgery and is the second most common cause of surgical revision [1]. Most of these infections are caused by coagulase-negative staphylococci or Staphylococcus aureus [1]. Conversely, Brucella infection of implants after total joint arthroplasty is an extremely rare situation [2-5]. We herein present the long-term results of two-stage revision knee arthroplasty due to TKA infection by Brucella melitensis.

\section{Case Report}

A 62-year-old man presented with a 4-month history of night sweats, high body temperature, and left knee pain in 2003. Two years previously, he had undergone a left TKA for treatment of gonarthrosis.

Upon examination, the knee appeared swollen, warm, and sore, and a sinus tract formation had developed at the incision area. Bacteriologic culture taken from the sinus tract discharge revealed B. melitensis. The patient's erythrocyte sedimentation rate (ESR) was $83 \mathrm{~mm} / \mathrm{h}$, C-reactive protein (CRP) level was $12.38 \mathrm{mg} / \mathrm{L}$, and blood leukocyte concentration was $9425 / \mathrm{mm}^{3}$. Plain radiography confirmed septic loosening (Figure 1).

A two-stage revision TKA was planned to correct the septic loosening of the implant. The first stage involved removal of the infected prosthesis and debridement of the remaining cement and

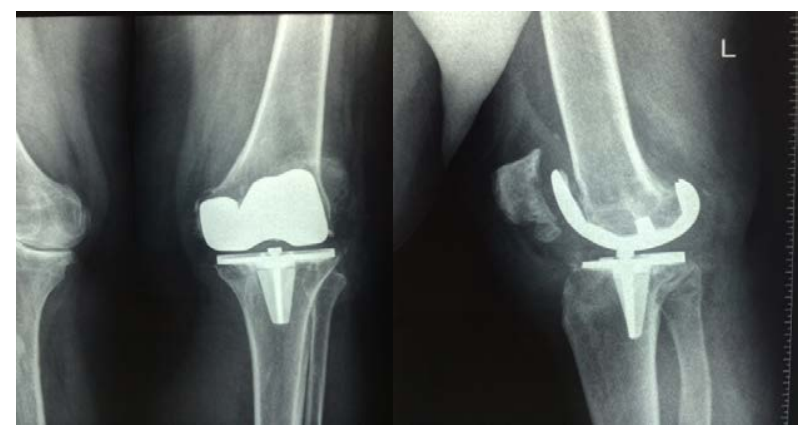

(a)

(b)

Figure 1: Anteroposterior and lateral plain radiography shows septic loosening necrotic tissue. Abundant purulent liquid was present in the knee joint, and both the femoral and tibial components were found to be loosened intraoperative. Frozen tissue pathology demonstrated both acute and chronic inflammation. Removal of the prosthetic components and cement and application of an antibiotic-loaded spacer (doxycycline and rifampicin -impregnated) were also performed in the first stage (Figure 2). Oral rifampicin $(900 \mathrm{mg}$ ) and doxycycline $(300 \mathrm{mg}$ ) were administered daily for 12 weeks postoperatively. At the end of the antibiotic therapy, the patient was seen as an outpatient, and his ESR, CRP level, and antibody titer had decreased toward normal values. Finally, prosthetic revision was performed in the second stage of the TKA. Ten years following surgery, the patient had returned to full activities of daily living, described no knee pain, and was very satisfied

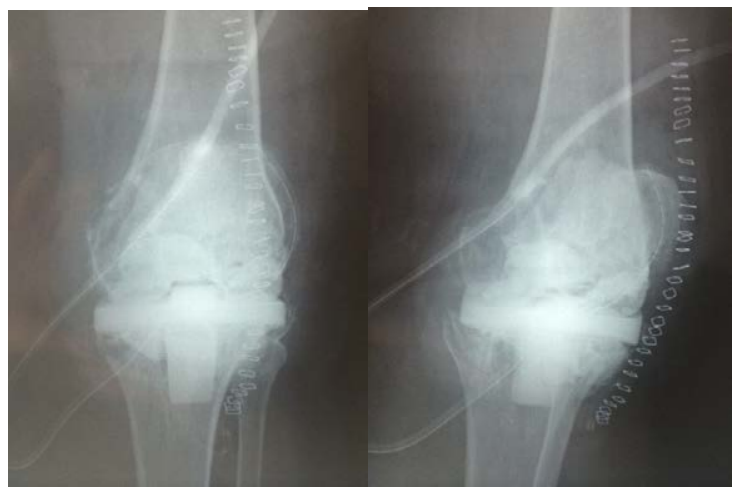

(a)

(b)

Figure 2: Plain radiography after the first stage

*Corresponding author: Dr. Fatih Karaaslan, Bozok Universitesi Tıp Fakültei Ortopedi ve Travmatoloji Bolumu, Yozgat, Turkey, Tel: +90 35421270 60; Fax: +90 35421270 60; E-mail: fkaraaslan@gmail.com

Received April 14, 2014; Accepted October 17, 2014; Published October 22 2014

Citation: Karaaslan F, Mermerkaya MU, Karaoğlu S, Ayvaz M. Total Knee Arthroplasty Infected by Brucella melitensis: Septic Loosening and Long-Term Results of Two-Stage Revision Knee Arthroplasty. Journal of Surgery [Jurnalul de chirurgie] 2014; 10(3): 241-242 DOI: 10.7438/1584-9341-10-3-8

Copyright: ( $) 2014$ Karaaslan F, et al. This is an open-access article distributed under the terms of the Creative Commons Attribution License, which permits unrestricted use, distribution, and reproduction in any medium, provided the original author and source are credited. 
with the outcome. No abnormalities associated with the femoral, tibial, or patellar components were observed on plain radiography 10 years following surgery (Figure 3). The results of a Brucella agglutination test at that time were negative.

\section{Discussion}

The incidence of infection following primary total hip or knee arthroplasty varies from $1.0 \%$ to $5.6 \%[1,2,6]$ and is mainly caused by aerobic Gram-positive microorganisms including coagulase-negative staphylococci and Staphylococcus Aureus. Gram-negative aerobic microorganisms and anaerobes are rare and account for less than $10 \%$ of infections. Fungal or mycobacterial infections are extremely unusual [6]. Brucellosis is a common zoonosis worldwide but predominantly affects Persian Gulf, South America, and Mediterranean countries. It is caused by a variety of microorganisms from the Brucella genus and can be transmitted by inoculation through the conjunctivae and through cuts and abrasions in the skin, or by ingestion of unpasteurized milk or infected dairy products. Brucellosis is a systemic infection with nonspecific symptoms such as sweating, anorexia, fatigue, weight loss, fever, lymphadenopathy, and hepatosplenomegaly [7]. Brucellosis is a disease with protean manifestations, which can be either acute or chronic. It is a systemic infection in which any organ in the body can be involved . Osteoarticular complications are common in brucellosis, having been reported in $10 \%-85 \%$ of cases . The spectrum of bone and joint complications includes arthritis, spondylitis, osteomyelitis, tenosynovitis, and bursitis. Sacroilitis was the most commonly reported complication in several studies [6-8] whereas large,weight-bearing joints were the most commonly involved joints in other series $[7,8]$.

Only a few cases of Brucella infection following total joint arthroplasty have been reported; thus, the most effective management remains unclear. Diagnosis is often difficult because patients usually present with no systemic symptoms. Only local symptoms (night pain, swelling, and suppuration) or mechanical loosening are typically present [4]. Adequate treatment depends on how and when the diagnosis is achieved.

Good results have been reported in three patients (two hips and one knee) treated with a two-stage procedure and antibiotic therapy (doxycycline $[100 \mathrm{mg}$ ] and rifampicin [ $600 \mathrm{mg}$ ] daily) for 6 weeks before and after reimplantation [4]. Good results were also obtained in total hip arthroplasty patients who underwent two-stage reimplantation using a longer preimplantation antibiotic scheme of streptomycin (1 $\mathrm{g}$ daily for 3 weeks), doxycycline (100 mg daily for 3 months), and rifampicin (600 mg daily for 3 months) without postimplantation antibiotics [8]. These results were nonetheless considered preliminary because of the very short follow-up period of less than 1 year.

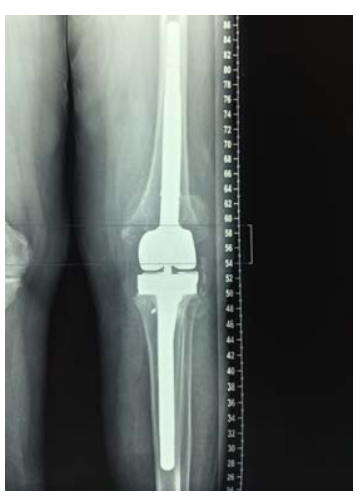

(a)

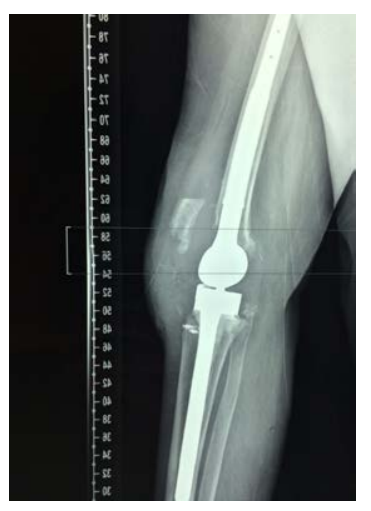

(b)
Jones et al. reported a total hip arthroplasty implant loosening caused by $B$. abortus that was treated successfully with one-stage reimplantation and antibiotic therapy for 1 year [8]; however, with a follow-up period of only 2 years, there is not yet enough evidence to recommend this course of treatment. Nevertheless, our knowledge of the surgical treatment of Brucella infection is limited to a few case reports with only total hip arthroplasty infection with a mid-term follow-up $[2,9,10]$. There are no previously reported long-term results of two-stage revision knee arthroplasty in a patient with a B. melitensisinfected TKA.

We believe that two-stage revision arthroplasty is the first-line treatment of a loosened TKA infected with $B$. melitensis. In addition, if a systemic Brucella infection is identified, the patient should be managed with two-stage revision surgery. We herein report an excellent longterm outcome with two-stage revision knee arthroplasty in a patient with a B. melitensis-infected TKA.

\section{Conclusion}

Osteoarticular disease related to Brucella remains a problem in endemic regions. Brucellosis should be kept in mind as a differential diagnosis of prosthetic joint infections, especially in patients with a history of brucellosis and exposure to possible sources of the bacteria.

\section{Conflict of interest}

The authors declare no conflicts of interest.

\section{Reference}

1. Hanssen AD, Rand JA (1999) Evaluation and treatment of infection at the site of a total hip or knee arthroplasty. Instr Course Lect 48: 111-122.

2. Kasim RA, Araj GF, Afeiche NE, Tabbarah ZA (2004) Brucella infection in total hip replacement: case report and review of the literature. Scand J Infect Dis 36: 65-67.

3. Tena D, Romanillos O, Rodríguez-Zapata M, de la Torre B, Pérez-Pomata MT, et al. (2007) Prosthetic hip infection due to Brucella melitensis: case report and literature review. Diagn Microbiol Infect Dis 58: 481-485.

4. Tena D, Romanillos $O$, Rodríguez-Zapata M, de la Torre B, Pérez-Pomata MT et al. (2007) Prosthetic hip infection due to Brucella melitensis: case report and literature review. Diagn Microbiol Infect Dis 58: 481-485.

5. Tena D, Romanillos O, Rodríguez-Zapata M, de la Torre B, Pérez-Pomata MT et al. (2007) Prosthetic hip infection due to Brucella melitensis: case report and literature review. Diagn Microbiol Infect Dis 58: 481-485.

6. Weil Y, Mattan Y, Liebergall M, Rahav G (2003) Brucella prosthetic join infection: a report of 3 cases and a review of the literature. Clin Infect Dis 36 : e81-86.

7. Erdogan H, Cakmak G, Erdogan A, Arslan H (2010) Brucella melitensis infection in total knee arthroplasty: a case report. Knee Surg Sports Traumatol Arthrosc 18: 908-910.

8. Salvati EA, González Della Valle A, Masri BA, Duncan CP (2003) The infected total hip arthroplasty. Instr Course Lect 52: 223-245.

9. Ariza J (2002) [Brucellosis in the 21st Century]. Med Clin (Barc) 119: 339-334.

10. Ortega-Andreu M1, Rodriguez-Merchan EC, Aguera-Gavalda M (2002) Brucellosis as a cause of septic loosening of total hip arthroplasty. J Arthroplasty 17: 384-387.

11. Jones RE, Berryhill WH, Smith J, Hofmann A, Rogers D (1983) Secondary infection of a total hip replacement with Brucella abortus. Orthopedics 6: 184-186.

12. Ruiz-Iban MA, Crespo P, Diaz-Peletier R, Rozado AM, Lopez-Pardo A (2006) Total hip arthroplasty infected by Brucella: a report of two cases. J Orthop Surg (Hong Kong) 14: 99-103.

Figure 3: Femoral, tibial, and patellar components on plain radiography 10 years after surgery 